\title{
JOGOS TEATRAIS APLICADOS À EDUCAÇÃO AMBIENTAL
}

Tális Pereira Matias ${ }^{1}$

Adriana Maria Imperador ${ }^{2}$

Resumo: O presente trabalho objetiva mostrar como e por que os jogos teatrais podem ser adaptados para a promoção da Educação Ambiental, considerando a proximidade entre os seus princípios e benefícios. Por meio de revisão bibliográfica qualitativa e análise crítica baseada no método dialético, foi possível desenvolver um quadro de jogos teatrais que atendem a demanda ambiental e do Teatro do Oprimido, que visam a libertação dos indivíduos de sistemas opressores e desiguais e buscam promover a emancipação e senso crítico. Com isso, verificou-se que os produtos provenientes desta união têm potencial transformador, podendo ser trabalhados por educadores ambientais, em diversos ambientes.

Palavras-chave: Dialética; Interdisciplinaridade; Sustentabilidade; Arte; Meio Ambiente.

Abstract: Our research aims to show how and why theatrical games can be adapted to promote Environmental Education, considering the proximity between its principles and benefits. Through a qualitative bibliographic review and critical analysis based on the dialectical method, it was possible to develop a framework of theatrical games that meet the environmental demand and the Theater of the Oppressed, which aim at the liberation of individuals from oppressive and unequal systems and seek to promote emancipation and critical sense. With that, we verified that the products coming from this union have transforming potential, being able to be worked by environmental educators, in different environments.

Keywords: Dialectic; Interdisciplinarity; Sustainability; Art; Environment.

${ }^{1}$ Universidade Federal de Alfenas. E-mail: talismatias12@gmail.com

2Universidade Federal de Alfenas. E-mail: adrianaimperador@yahoo.com.br

Revbea, São Paulo, V.16, № 5: 532-546, 2021. 


\section{Introdução}

Os desafios ambientais estabelecem conexões entre diversos meios sociais, incluindo a escola e as comunidades, que são locais ricos em variados tipos de transações sociais. Neste contexto, o trabalho de educadores ambientais que atuam em diferentes esferas da educação formal e não formal de forma crítica e inclusiva, é fundamental. Para isso, existem muitas alternativas que podem ser utilizadas a favor de processos educativos, dentre elas, as ferramentas teatrais, que apresentam princípios com relações estreitas com a Educação Ambiental (LI; KRASNY, 2019; VIEIRA, 2010).

Esses princípios norteiam o rumo a ser seguido por estes dois ramos do conhecimento, que se referem à ética, ao engajamento comunitário e à construção de valores fundamentais para a ressignificação e quebra de paradigmas obsoletos que não são benéficos ao desenvolvimento sustentável.

Dentro da prática teatral destacam-se os jogos teatrais que podem estimular a criatividade, promover o senso crítico, fortalecer o sentimento de pertencimento e ser utilizados para uma ampla gama de aspectos, que abarcam desde problemas políticos e socioeconômicos até questões ambientais, culturais e de saúde pública (ANDRIKOPOULOU; KOUTROUBA, 2017; LYKESAS et al., 2018).

Todas essas questões correlacionam-se com a Educação Ambiental, e frisam a importância da interdisciplinaridade na busca de processos educativos que melhorem a qualidade de vida e bem-estar individual e coletivo (HOELLER; FAGUNDES, 2020). Para tanto, encontrar métodos aplicados que trabalhem a realidade das comunidades garantindo o envolvimento dos agentes que ali coexistem, é uma medida relevante para a versatilidade do trabalho do educador ambiental.

Desta forma, por meio de pesquisa bibliográfica, o presente trabalho tem como objetivo responder como e por que a adaptação de jogos teatrais voltados para a Educação Ambiental pode ser aplicada para o preparo do cidadão para melhorar a sua relação com o meio ambiente, reconhecendo-se como agente pertencente e cocriador da sua própria realidade.

\section{Metodologia}

Este artigo deriva de pesquisas bibliográficas qualitativas realizadas em plataformas especializadas de busca, SciELO e Google Acadêmico, de artigos e livros didáticos e científicos que versam sobre as relações entre jogos teatrais e Educação Ambiental, direta ou indiretamente, nos últimos 20 anos.

Foi considerada como relação direta, artigos e trabalhos que discorram sobre Educação Ambiental e Teatro, enquanto os trabalhos indiretos foram aqueles que fornecem suporte para o estabelecimento de relações entre os paradigmas das duas disciplinas, sem necessariamente, falar sobre as duas formas de saber de forma conjunta no mesmo trabalho. 
A abordagem deste trabalho segue o método dialético (MARCONI; LAKATOS, 2003) direcionado para o desenvolvimento de um quadro com adaptações de jogos teatrais voltados para a Educação Ambiental a partir dos trabalhos científicos levantados.

As buscas foram realizadas com a finalidade de encontrar relações entre os princípios da Educação Ambiental e do Teatro do Oprimido, visando destacar os benefícios dos jogos teatrais e sua aplicabilidade na Educação Ambiental em consonância com o desenvolvimento cognitivo individual e coletivo.

Para isso, foram utilizadas palavras-chave: Educação Ambiental e Teatro; Teatro do Oprimido e Educação Ambiental; Teatro e Inteligências; Jogos Teatrais e Educação Ambiental; para buscas de relações diretas, enquanto que para as buscas de relações indiretas considerou-se as palavras isoladas, dando preferência para trabalhos publicados nos últimos cinco anos, salvo aqueles cujo a obra é referência na disciplina.

Para a definição dos artigos indiretos que seriam utilizados nesta pesquisa realizou-se a leitura do Título, resumo e palavras-chave dos trabalhos encontrados, buscando semelhanças entre os princípios de cada temática abordada, para que fosse possível traçar pontos em comum que permitissem a adaptação de jogos teatrais às práticas de Educação Ambiental.

\section{Resultados e Discussão}

Quando a palavra-chave "Teatro do Oprimido e Educação Ambiental" foi utilizada no SciELO, apenas o artigo de Silveira (2009) foi mostrado. Já para a palavra-chave "Teatro e Inteligências" e "Jogos Teatrais e Educação Ambiental" nenhum trabalho foi apontado. Apenas 3 artigos científicos foram encontrados para a busca por "Educação Ambiental e Teatro" (Quadro 1). Em inglês, os mesmos resultados foram encontrados.

\begin{tabular}{|c|c|c|}
\hline \multicolumn{3}{|c|}{ SCIELO } \\
\hline № de trabalhos: & 3 & \\
\hline Título & Autor & $\begin{array}{l}\text { Informações } \\
\text { bibliográficas }\end{array}$ \\
\hline $\begin{array}{l}\text { Morcegos: percepção dos } \\
\text { alunos do Ensino } \\
\text { Fundamental } 3^{\circ} \text { e } 4^{\circ} \\
\text { ciclos e práticas de } \\
\text { Educação Ambiental }\end{array}$ & $\begin{array}{l}\text { Silva, Sérgio Gomes da; Manfrinato, Márcia } \\
\text { Helena Vargas; Anacleto, Teresa Cristina da } \\
\text { Silveira. Citaçâo: (SÉRGIO GOMES DA; } \\
\text { MÁRCIA HELENA VARGAS; TERESA } \\
\text { CRISTINA DA SILVEIRA, 2013) }\end{array}$ & $\begin{array}{c}\text { Ciência \& } \\
\text { Educação (Bauru) } \\
\text { 2013, Volume 19 } \\
\text { № 4 Páginas } 859 \text { - } \\
877\end{array}$ \\
\hline $\begin{array}{l}\text { Teatro de fantoches na } \\
\text { formação continuada } \\
\text { docente em Educação } \\
\text { Ambiental }\end{array}$ & $\begin{array}{c}\text { Dantas, Osmarina Maria dos } \\
\text { Santos; Santana, André Ribeiro } \\
\text { de; Nakayama, Luiza. Citação: (DANTAS; DE } \\
\text { SANTANA; NAKAYAMA, 2012) }\end{array}$ & $\begin{array}{c}\text { Educação e } \\
\text { Pesquisa Set 2012, } \\
\text { Volume } 38 \text { № 3 } \\
\text { Páginas } 711-726\end{array}$ \\
\hline $\begin{array}{l}\text { A arte do encontro: a } \\
\text { Educação Estética } \\
\text { Ambiental atuando com o } \\
\text { Teatro do Oprimido }\end{array}$ & Silveira, Eduardo. Citação:(SILVEIRA, 2009) & $\begin{array}{c}\text { Educação em } \\
\text { Revista Dez } 2009, \\
\text { Volume } 25 \text { № } 3 \\
\text { Páginas } 369 \text { - } 394\end{array}$ \\
\hline
\end{tabular}

Fonte: Dos autores. 
Utilizando o Google Acadêmico, os trabalhos encontrados foram de 5.500 resultados para "Teatro do Oprimido e Educação Ambiental" 12.100 resultados para "Teatro e Inteligências" 11.500 resultados para "Jogos Teatrais e Educação Ambiental" 15.600 resultados para "Educação Ambiental e Teatro" nos últimos 5 anos.

\section{Uma aliança entre a Educação Ambiental e o Teatro do Oprimido}

Todos os indivíduos pertencem e estão inseridos nas dinâmicas dos territórios geográficos com questões geopolíticas, históricas, culturais e características próprias, entretanto, nem sempre existe a percepção de coexistência com os demais elementos que compõe o lugar em que se vive, o que enfatiza o fortalecimento de estratégias de Educação Ambiental para a conservação dos recursos naturais, promoção do desenvolvimento sustentável e qualidade de vida (HERNÁNDEZ GARZÓN, 2019, p.112).

Desde a implementação da Política Nacional de Educação Ambiental PNEA (Lei Federal no 9.785/1999) avanços e retrocessos têm sido observados. Garcia, et al. (2020) concluem, que neste contexto, é fundamental que a Educação Ambiental se torne cada vez mais popular, crítica e emancipatória, independentemente da pactuação do governo federal com tal princípio. Os autores também destacam a urgência da constituição de um conjunto social articulado que não abandone as diretrizes da PNEA e que resgatem o processo dialético entre estado e sociedade.

Relacionando a importância da autonomia e articulação das comunidades em lidar com suas próprias demandas, é importante que haja alternativas eficazes na promoção da interação, participação e autonomia nas decisões locais, que independam do estado, mas que possam ser incentivadas pelo mesmo, considerando que haja disposição política para isso (GARCIA et al., 2020). Neste sentido, técnicas e dinâmicas teatrais podem ser utilizadas no contexto comunitário, principalmente os jogos teatrais derivados do Teatro do Oprimido, desenvolvido por Augusto Boal em 1970 no Brasil, e com forte afinidade com os princípios trabalhados nas obras de Paulo Freire (CARNEIRO; GONÇALVES, 2015).

Por ser uma prática que busca lidar com as emergências sociais e com o conhecimento coletivo, o Teatro do Oprimido apresenta-se como forte aliado da Educação Ambiental, sendo uma união entre duas linhas do conhecimento que, de forma interdisciplinar, pode contribuir para a "pesquisa-ação-participativa" e transformação social (NOGUEIRA CAMPOS; PANÚNCIO-PINTO; SAEKI, 2014; SILVEIRA, 2009).

Os jogos teatrais desenvolvidos por este ramo da arte são praticados em mais de setenta países, por pessoas com total diversidade de gênero, faixa etária, etnia, cultura e profissão, com o enfoque no desenvolvimento humano por meio da arte, buscando a valorização dos saberes populares e coletivos e o reencontro com o mundo que os cerca (NOGUEIRA CAMPOS; PANÚNCIO- 
PINTO; SAEKI, 2014; SILVEIRA, 2009). Além disso, existem diversos estudos realizados que corroboram para o uso interdisciplinar de atividades teatrais, variando desde análises de psicologia social (OLIVEIRA; ARAÚJO, 2012; VIEIRA, 2010), até relações e benefícios aplicados na educação (CARLOS et al., 2018; CARNEIRO; GONÇALVES, 2015; FANTIN; MALCUT, 2019) e nas ciências ambientais (OLIVEIRA, 2012; PINTO; MOREIRA, 2019).

Outro fator fundamental a ser trabalhado é o contexto político, que constitui parte significativa da essência do Teatro do Oprimido, embasado sempre na luta contra a opressão, exploração, dominação e manipulação, buscando no discurso dialético a promoção da libertação e emancipação para superar os desafios associados ao desemprego, austeridade, desigualdade e efeitos do capitalismo (BARBOSA; FERREIRA, 2017), de forma semelhante às pautas enfrentadas pela Educação Ambiental, que também demandam urgência e ação política nas questões associadas ao meio ambiente, conservação e sustentabilidade, que afetam direta e indiretamente a saúde e bem-estar da população e necessitam de atenção e participação social (GARCIA et al., 2020; MATIAS; MAESTEGHIN; IMPERADOR, 2020).

Hoeller e Fagundes (2020, p.227) defendem que:

Defendemos uma Educação Ambiental vinculada à vida das pessoas dos lugares, construindo caminhos, que ao lerem seus processos de realidade, conhecem, se reconhecem em um sistema opressor. Ao construírem conhecimentos por meio da ação, constroem processos de consciência de seu papel social e político em suas comunidades e com o meio em que vivem. Constroem juntos, dialogam e avançam nesse conhecimento na leitura do mundo e dos conhecimentos sistematizados. Não há superposição, não há espaço para o verbalismo, porque o conhecimento vai se produzindo enraizado em suas realidades locais. Há um processo democrático de Educação Ambiental popular.

Ficam claras as relações e afinidades entre os princípios nestas duas áreas do conhecimento, que podem ser utilizadas de forma conjunta, enfatizando os desafios sociais, políticos, econômicos, culturais e ambientais que devem ser superados para que tais práticas se sobreponham ao sistema capitalista associado ao consumismo e aos diversos impactos que dele derivam (CARVALHO, 2020; HOELLER; FAGUNDES, 2020; LI; KRASNY, 2019)

Desta forma, traçar estratégias embasadas em técnicas do Teatro do Oprimido com aplicação na Educação Ambiental, é um caminho promissor a ser trabalhado pelos educadores ambientais, uma vez que essas práticas trazem a proposta de promover o diálogo dentro de uma ação prática, que é a própria a manifestação teatral (CARLOS et al., 2018; SILVEIRA, 2009).

A aliança entre as práticas de Educação Ambiental e do Teatro do 
explorada e aplicada para fortalecer a implementação da Política Nacional de Educação Ambiental, reunindo esforços para promover maior representatividade dos indivíduos em suas comunidades, considerando as suas diferentes formas de saber e de se expressar.

\section{Os diferentes tipos de "inteligências" estimulados pelos jogos teatrais}

O processo de ensino-aprendizagem envolve múltiplos fatores que influenciam na construção do conhecimento, e é importante considerar que existem diferentes tipos de competências cognitivas em cada indivíduo (LIMA; DOMINGUES; VIDOTTI, 2018). Essas "inteligências", que referem-se a capacidade da resolução de problemas e criação de produtos válidos em diferentes aspectos culturais, podem ser divididas em nove tipos: naturalista, lógico-matemática, linguística, espacial, corporal-cinestésica, musical, interpessoal, intrapessoal e existencialista (DENIG, 2004; LIMA; DOMINGUES; VIDOTTI, 2018).

Em todas elas, os jogos teatrais podem atuar, potencializando habilidades naturais e estimulando o aperfeiçoamento e desenvolvimento dos demais tipos de inteligências (Figura 1). Tal prática, aliada ao trabalho cognitivo, auxilia na ampliação da consciência cultural, além de ser uma importante ferramenta pedagógica que contribui para fortalecer os laços de comunicação, pensamento crítico, responsabilidade, tolerância, respeito pelas ideias e pontos de vista divergentes, trabalho em equipe e cooperação, auxiliando também, na criação de ambientes favoráveis ao processo de aprendizagem (LYKESAS et al., 2018).

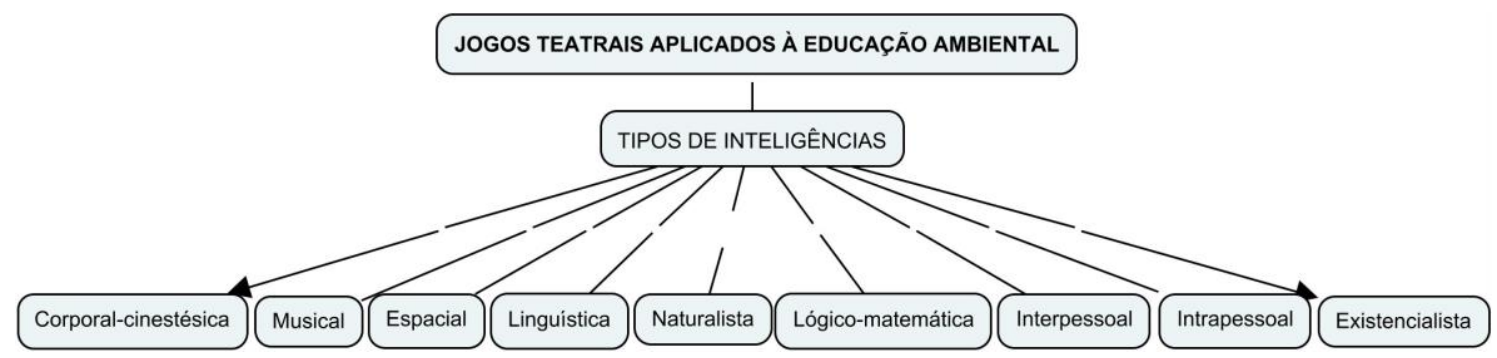

Figura 1. Tipos de inteligências que podem ser trabalhadas por meio de jogos teatrais e Educação Ambiental. Fonte: Dos autores.

Conforme ilustra a Figura 1, todos os tipos de inteligências podem ser trabalhadas através da realização de jogos teatrais aplicados a Educação Ambiental, entretanto, para que isso aconteça, é importante observar a importância da multi e interdisciplinaridade abordada nos jogos, recrutando esforços para que os participantes manifestem as suas habilidades, compartilhem o saber e multipliquem o conhecimento.

As práticas teatrais atuam através de diferentes formas e provocam uma variada gama de emoções e sensações, permitindo aos envolvidos vivenciar 
novas experiências, desenvolver a empatia e analisar determinado tema por meio de visões múltiplas. Essas vivências manifestadas por meio de processos teatrais permitem o estímulo cognitivo em todos os tipos de inteligências, possibilitando aos envolvidos vivenciar experiências nos diferentes campos do conhecimento (IRANMADAR; BOZORGMEHR; SEPAHVAND, 2017).

Um estudo bibliográfico realizado durante a pandemia provocada pelo novo coronavírus no ano de 2020 (CHEMI et al., 2020) mostra a importância das práticas teatrais, frisando a versatilidade de tais atividades. Os autores também destacam vários trabalhos que demonstram a efetividade dos jogos teatrais para o aprimoramento intelectual e desenvolvimento de senso crítico, enfatizando também os prejuízos causados pelo isolamento social que poderiam ser melhorados por meio de interações sociais e práticas teatrais.

Aos educadores, cabe reconhecer estes aspectos e a importância da multi e interdisciplinaridade no processo de aprendizado, ensinando e aplicando métodos que levem os indivíduos de um estado passivo para ativo, de espectador para protagonista de sua própria realidade, buscando a melhoria das relações sociais ancorados em fundamentos éticos e embasados no respeito aos direitos humanos e cidadania (IRANMADAR; BOZORGMEHR; SEPAHVAND, 2017).

É neste sentido que emerge a importância da adaptação dos jogos teatrais apreciados pelo Teatro do Oprimido para a prática da Educação Ambiental, com o objetivo de lidar com a problemática ambiental e com as suas variáveis interdisciplinares de forma proativa, possibilitando ao indivíduo e à coletividade a ampliação do seu potencial cognitivo, a construção de valores sociais, conhecimentos, habilidades, atitudes e competências focadas na conservação do meio ambiente, sadia qualidade de vida e sustentabilidade, conforme recomenda a Política Nacional de Educação Ambiental (BRASIL, 1999).

\section{Adaptação de jogos teatrais para a promoção da Educação Ambiental}

Para Boal (2010) o teatro deve ser considerado um ensaio para a vida real, e não um fim em si mesmo. Os jogos teatrais apresentam características essenciais da vida em sociedade, pois possuem regras, assim como a sociedade possui leis, entretanto, necessitam de liberdade criativa, para que a vida não se resuma em servil escravidão. Segundo as palavras do próprio autor, fundador do Teatro do Oprimido, "Sem regras não há jogo, sem liberdade não há vida."

O desenvolvimento e prática dos jogos teatrais para a promoção da Educação Ambiental deve abordar problemas relevantes levantados pelos jogadores, incluindo os aspectos políticos com o objetivo geral de estimular o senso crítico, autonomia e liberdade de expressão. Desta forma, o Quadro 2 mostra um conjunto de jogos teatrais e seus respectivos objetivos. 
Quadro 2: Jogos teatrais adaptados para a promoção da Educação Ambiental.

\begin{tabular}{|c|c|c|}
\hline JOGOS & DESCRIÇÃO & OBJETIVO \\
\hline Aquecimento & $\begin{array}{l}\text { Deve ser realizado sempre antes de começar } \\
\text { as dinâmicas, consiste em aquecimentos } \\
\text { físicos aplicados às atividades teatrais. }\end{array}$ & $\begin{array}{c}\text { Relaxar e aquecer o corpo para } \\
\text { realização de movimentos com } \\
\text { saúde e segurança; } \\
\text { desmecanização corporal. }\end{array}$ \\
\hline $\begin{array}{l}\text { Roda de } \\
\text { conversa }\end{array}$ & $\begin{array}{c}\text { Os participantes devem se sentar em círculo e } \\
\text { relatar observações sobre aspectos e impactos } \\
\text { ambientais em sua região e rotina. Por meio de } \\
\text { uma abordagem dialógica, problemas } \\
\text { socioambientais, políticos e econômicos são } \\
\text { levantados. }\end{array}$ & $\begin{array}{l}\text { Promover a troca de } \\
\text { informações, integração, } \\
\text { participação e promover o } \\
\text { diálogo crítico sobre questões } \\
\text { relevantes e que podem oprimir } \\
\text { os indivíduos. } \\
\end{array}$ \\
\hline Espelho & $\begin{array}{r}\text { Em duplas, uma pessoa } \\
\text { outro o copia como um } \\
\text { sugerir a inclusão de qu } \\
\text { cotidianas, como desp } \\
\text { descarte inadequad }\end{array}$ & $\begin{array}{c}\text { Incentivar a integração, } \\
\text { descontração, criatividade e } \\
\text { estimular um novo enfoque } \\
\text { sobre os elementos trabalhados. }\end{array}$ \\
\hline $\begin{array}{l}\text { Percebendo o } \\
\text { outro }\end{array}$ & $\begin{array}{l}\text { Em duplas, os participantes se observam por } \\
\text { um tempo, depois um vira de costas enquanto } \\
\text { o outro modifica algo na sua aparência, ao } \\
\text { retornar, o participante deve identificar o que foi } \\
\text { alterado. }\end{array}$ & $\begin{array}{l}\text { Estimular a observação, } \\
\text { atenção e integração, e } \\
\text { ressaltar a importância destas } \\
\text { ações no dia-a-dia. }\end{array}$ \\
\hline $\begin{array}{l}\text { Sentindo o } \\
\text { espaço }\end{array}$ & $\begin{array}{l}\text { Os participantes, em duplas, um vendado e } \\
\text { outro não, devem percorrer o espaço. O guia } \\
\text { deve levar o colega vendado em locais } \\
\text { diferentes para que ele toque e sinta os } \\
\text { elementos do ambiente. }\end{array}$ & $\begin{array}{c}\text { Trabalhar o aparelho } \\
\text { psicomotor, a confiança e a } \\
\text { sensibilidade táctil; introduzir } \\
\text { aspectos de pertencimento } \\
\text { ambiental. }\end{array}$ \\
\hline $\begin{array}{l}\text { Percebendo o } \\
\text { ambiente }\end{array}$ & $\begin{array}{c}\text { Preferencialmente em local aberto e com } \\
\text { natureza, os participantes devem observar o } \\
\text { espaço e memorizar o cenário. Depois, o } \\
\text { moderador questionará o que eles se } \\
\text { recordam. }\end{array}$ & $\begin{array}{l}\text { Estimular a observação, } \\
\text { memória e proporcionar } \\
\text { reflexões sobre o pertencimento } \\
\text { ambiental e as implicações dos } \\
\text { elementos que compõe o } \\
\text { ambiente. }\end{array}$ \\
\hline $\begin{array}{l}\text { Leitura } \\
\text { ambiental }\end{array}$ & $\begin{array}{l}\text { O coordenador separa alguns trechos de textos } \\
\text { e espalha pelo cenário. Um de cada vez, os } \\
\text { alunos devem entrar em cena, sortear um texto } \\
\text { e começar a ler em voz alta e de forma } \\
\text { peculiar. }\end{array}$ & $\begin{array}{l}\text { Treinar a dicção vocal; estimular } \\
\text { a autoconfiança; introduzir } \\
\text { conceitos ambientais } \\
\text { importantes. }\end{array}$ \\
\hline $\begin{array}{l}\text { Jogo de } \\
\text { palavras }\end{array}$ & $\begin{array}{c}\text { Em círculos. Um colega fala uma palavra, o } \\
\text { segundo completa com outra coerente com a } \\
\text { do primeiro, o terceiro completa com outra } \\
\text { coerente à do segundo e assim } \\
\text { sucessivamente. }\end{array}$ & $\begin{array}{c}\text { Manter a coerência sobre a } \\
\text { temática ambiental e ampliar os } \\
\text { conhecimentos sobre meio } \\
\text { ambiente. }\end{array}$ \\
\hline $\begin{array}{l}\text { Processo } \\
\text { ambiental }\end{array}$ & $\begin{array}{l}\text { Um jogador cria um movimento como se fosse } \\
\text { parte de um processo industrial, os demais vão } \\
\text { entrando em cena, um a um, compondo o } \\
\text { processo até a formação de um produto. }\end{array}$ & $\begin{array}{c}\text { Promover a compreensão sobre } \\
\text { processos industriais e levantar } \\
\text { os possíveis aspectos e } \\
\text { impactos ambientais deste } \\
\text { processo. }\end{array}$ \\
\hline $\begin{array}{l}\text { Alfabeto } \\
\text { ambiental }\end{array}$ & $\begin{array}{l}\text { Em círculo, os jogadores devem, um de cada } \\
\text { vez, falar a primeira palavra no contexto } \\
\text { ambiental que Ihes vier à cabeça, em ordem } \\
\text { alfabética. Cada pessoa fala apenas uma } \\
\text { palavra até rodar o círculo. }\end{array}$ & $\begin{array}{c}\text { Despertar a atenção dos } \\
\text { participantes para questões } \\
\text { ambientais e aprofundar o } \\
\text { conhecimento sobre as palavras } \\
\text { que emergirem. }\end{array}$ \\
\hline
\end{tabular}

Continua...

Revbea, São Paulo, V.16, № 5: 532-546, 2021. 


\begin{tabular}{|c|c|c|}
\hline JOGOS & DESCRIÇÃO & OBJETIVO \\
\hline $\begin{array}{l}\text { Caminhada } \\
\text { com } \\
\text { obstáculos }\end{array}$ & $\begin{array}{l}\text { Os jogadores devem caminhar pelo espaço } \\
\text { representando, dentro do cenário imaginário, } \\
\text { uma cena proposta pelo moderador. A cena } \\
\text { deve abarcar aspectos relevantes para lidar } \\
\text { com a problemática ambiental. Ex: Andar em } \\
\text { uma praia poluída. }\end{array}$ & $\begin{array}{l}\text { Promover a criatividade, } \\
\text { interação, expressão e reflexão } \\
\text { sobre os temas ambientais } \\
\text { abordados e os seus efeitos } \\
\text { sobre o meio ambiente. }\end{array}$ \\
\hline $\begin{array}{l}\text { Conversa } \\
\text { ambiental }\end{array}$ & $\begin{array}{c}\text { Até } 5 \text { participantes por vez. O moderador } \\
\text { descreve um cenário e os jogadores devem } \\
\text { desenvolver um diálogo coerente com o } \\
\text { assunto dentro desse cenário. }\end{array}$ & $\begin{array}{l}\text { Abordar questões ambientais } \\
\text { relevantes como poluição, } \\
\text { desmatamento, crimes } \\
\text { ambientais, ecologia e } \\
\text { sustentabilidade. }\end{array}$ \\
\hline $\begin{array}{l}\text { Palavra- } \\
\text { chave }\end{array}$ & $\begin{array}{l}\text { Até } 3 \text { jogadores por vez. O moderador deve } \\
\text { sugerir uma palavra e os participantes devem } \\
\text { gerar um diálogo coerente e com um contexto } \\
\text { para alocar a palavra três vezes na conversa. }\end{array}$ & $\begin{array}{l}\text { Desenvolver o raciocínio } \\
\text { ambiental, criatividade e } \\
\text { improviso. }\end{array}$ \\
\hline $\begin{array}{l}\text { Telefone sem } \\
\text { fio por mimica }\end{array}$ & $\begin{array}{c}\text { Todos jogam. Em fila, o primeiro jogador } \\
\text { desenvolve uma mímica sobre algum aspecto } \\
\text { ou impacto ambiental que deve ser transmitido } \\
\text { até o último da fila que revelará o seu resultado } \\
\text { final. }\end{array}$ & $\begin{array}{l}\text { Criatividade, expressão } \\
\text { corporal, aprofundamento dos } \\
\text { conteúdos teóricos e } \\
\text { comunicação. }\end{array}$ \\
\hline Cena guiada & $\begin{array}{l}\text { O moderador indica um tema, situação, } \\
\text { contexto e personagens e os jogadores devem } \\
\text { desenvolver uma cena com começo meio e fim. }\end{array}$ & $\begin{array}{c}\text { Orientar e direcionar } \\
\text { conhecimentos específicos } \\
\text { fundamentais para o lidar com } \\
\text { problemas socioambientais e } \\
\text { políticos } \\
\end{array}$ \\
\hline $\begin{array}{l}\text { Blablação } \\
\text { ambiental }\end{array}$ & $\begin{array}{l}\text { Em duplas. Os participantes devem começar } \\
\text { um diálogo ambiental e quando o coordenador } \\
\text { der o sinal devem conversar em "blabla", ao } \\
\text { próximo sinal continuam o diálogo de onde } \\
\text { pararam. }\end{array}$ & $\begin{array}{l}\text { Introduzir a problemática } \\
\text { ambiental de forma simples e } \\
\text { interativa estimulando a } \\
\text { inteligência. }\end{array}$ \\
\hline Dicionário & $\begin{array}{c}\text { O coordenador indica palavras-chave e os } \\
\text { jogadores devem dizer o significado daquela } \\
\text { palavra, conforme o seu entendimento, como } \\
\text { se fosse em um dicionário, depois, debate-se o } \\
\text { tema. }\end{array}$ & $\begin{array}{l}\text { Trabalhar a percepção } \\
\text { ambiental dos indivíduos e } \\
\text { como eles expressam o seu } \\
\text { conhecimento. }\end{array}$ \\
\hline $\begin{array}{l}\text { Narrador e } \\
\text { intérprete }\end{array}$ & $\begin{array}{c}\text { Em duplas ou trios. Um jogador narra uma } \\
\text { cena da sua realidade cotidiana associada ao } \\
\text { meio ambiente e os outros interpretam a cena } \\
\text { com mímica. }\end{array}$ & $\begin{array}{c}\text { Trazer a realidade dos alunos à } \\
\text { tona, investigar e estimular a } \\
\text { percepção ambiental e } \\
\text { problematização ambiental. }\end{array}$ \\
\hline $\begin{array}{l}\text { Narrador e } \\
\text { intérprete } \\
\text { invertido }\end{array}$ & $\begin{array}{c}\text { Em grupos. Alguns jogadores representam } \\
\text { uma situação, em mímica, enquanto o outro } \\
\text { descreve o que está acontecendo na cena a } \\
\text { partir do seu entendimento da mímica dos } \\
\text { colegas. }\end{array}$ & $\begin{array}{l}\text { Trazer a realidade dos } \\
\text { participantes à tona, investigar e } \\
\text { estimular a percepção ambiental } \\
\text { e problematização ambiental. }\end{array}$ \\
\hline $\begin{array}{l}\text { Lidando com } \\
\text { resíduos } \\
\text { sólidos }\end{array}$ & $\begin{array}{l}\text { Algum resíduo sólido é colocado no meio do } \\
\text { cenário, em seguida, os alunos devem começar } \\
\text { uma cena com começo, meio e fim, tendo o } \\
\text { resíduo como objeto central da cena. }\end{array}$ & $\begin{array}{l}\text { Abordar a problemática dos } \\
\text { resíduos sólidos. }\end{array}$ \\
\hline
\end{tabular}

Continua...

Revbea, São Paulo, V.16, № 5: 532-546, 2021. 
...continuação.

\begin{tabular}{|c|c|c|}
\hline JOGOS & DESCRIÇÃO & OBJETIVO \\
\hline $\begin{array}{l}\text { Acrescentar } \\
\text { uma parte }\end{array}$ & $\begin{array}{l}\text { Entre } 5 \text { e } 10 \text { jogadores por vez. O primeiro } \\
\text { jogador inicia uma cena e em seguida se } \\
\text { retira, o próximo entra e compõe outra parte, } \\
\text { até que a cena final seja concluída. }\end{array}$ & $\begin{array}{c}\text { Desenvolver a linguagem não } \\
\text { verbal, criatividade, cooperação } \\
\text { e reflexão sobre os temas } \\
\text { representados. } \\
\end{array}$ \\
\hline $\begin{array}{l}\text { Jogo dos } \\
\text { nomes }\end{array}$ & $\begin{array}{l}\text { Duas equipes. Sorteia-se uma letra do } \\
\text { alfabeto e a equipe deve falar um aspecto ou } \\
\text { impacto ambiental com aquela letra e explicar } \\
\text { o seu entendimento sobre o assunto. }\end{array}$ & $\begin{array}{l}\text { Aprofundar os conhecimentos } \\
\text { sobre aspectos e impactos } \\
\text { ambientais e avaliar o } \\
\text { conhecimento prévio dos } \\
\text { participantes sobre o conteúdo. }\end{array}$ \\
\hline $\begin{array}{l}\text { Criando } \\
\text { aspectos } \\
\text { ambientais }\end{array}$ & $\begin{array}{c}\text { Equipes de até } 5 \text { pessoas. Os participantes } \\
\text { devem planejar uma cena mostrando algum } \\
\text { aspecto ambiental. Os demais devem } \\
\text { identificar o aspecto e relacionar ao seu } \\
\text { impacto ambiental. }\end{array}$ & $\begin{array}{l}\text { Entender diferentes tipos de } \\
\text { processos que causam } \\
\text { aspectos e impactos } \\
\text { ambientais. }\end{array}$ \\
\hline $\begin{array}{l}\text { Improviso com } \\
\text { a última palavra }\end{array}$ & $\begin{array}{l}\text { O coordenador diz uma palavra e o jogador } \\
\text { deve completar com o que lhe vier na mente } \\
\text { buscando ser o mais coerente possível. }\end{array}$ & $\begin{array}{l}\text { Detectar o conhecimento dos } \\
\text { participantes sobre o tema } \\
\text { proposto e estimular o } \\
\text { pensamento rápido e coerente. }\end{array}$ \\
\hline $\begin{array}{l}\text { Cena ambiental } \\
\text { em câmera } \\
\text { lenta }\end{array}$ & $\begin{array}{r}\text { Os jogadores devem } \\
\text { câmera lenta que repr } \\
\text { impacto ambiental ind } \\
\text { e/ou com t }\end{array}$ & $\begin{array}{r}\text { Estimular o traba } \\
\text { e sincronia na } n \\
\text { das percepções s } \\
\text { e impactos a }\end{array}$ \\
\hline Jogo do troca & $\begin{array}{l}\text { Os participantes interpretam cenas com } \\
\text { contextos ambientais variados. Quando o } \\
\text { moderador disser a palavra "troca" a última } \\
\text { pessoa que falou deve trocar a sua última } \\
\text { frase por outra também coerente. }\end{array}$ & $\begin{array}{c}\text { Estimular o pensamento rápido } \\
\text { e crítico para lidar com } \\
\text { questões como impactos } \\
\text { ambientais, situações de risco } \\
\text { e perigo ambiental. }\end{array}$ \\
\hline $\begin{array}{c}\text { Cenas } \\
\text { improváveis }\end{array}$ & $\begin{array}{l}\text { Os participantes escrevem várias frases de } \\
\text { situações que representem problemas } \\
\text { socioambientais, sorteiam-se as frases entre } \\
\text { os grupos e eles devem começar uma cena } \\
\text { com a frase sorteada. }\end{array}$ & $\begin{array}{l}\text { Vivenciar e simular situações } \\
\text { ambientais, de forma lúdica e } \\
\text { descontraída, buscando } \\
\text { soluções para as questões } \\
\text { levantadas. }\end{array}$ \\
\hline Jogo das frases & $\begin{array}{c}\text { O coordenador orienta uma cena, os } \\
\text { jogadores desenvolvem, e ao sinal, eles } \\
\text { devem tirar uma frase prescrita do bolso e } \\
\text { incorporar ao contexto da cena da forma mais } \\
\text { coerente possível. }\end{array}$ & $\begin{array}{c}\text { Incluir variedade de temas e } \\
\text { abordagens associados às } \\
\text { questões ambientais, sociais, } \\
\text { econômicas, políticas e } \\
\text { culturais. }\end{array}$ \\
\hline Cena livre & $\begin{array}{l}\text { Os jogadores devem criar uma cena com } \\
\text { começo, meio e fim sobre uma pauta } \\
\text { ambiental que considerem significativa. }\end{array}$ & $\begin{array}{c}\text { Discutir e ampliar os } \\
\text { conhecimentos sobre os temas } \\
\text { ambientais levantados pelos e } \\
\text { promover a criatividade e } \\
\text { interação lúdica. }\end{array}$ \\
\hline $\begin{array}{l}\text { Viagens } \\
\text { imaginárias }\end{array}$ & $\begin{array}{l}\text { Os jogadores, devem interpretar e buscar } \\
\text { vivenciar uma história, em tempo real, } \\
\text { contada pelo narrador. }\end{array}$ & $\begin{array}{c}\text { Sensibilizar os participantes } \\
\text { para o tema escolhido para a } \\
\text { viagem imaginária. }\end{array}$ \\
\hline
\end{tabular}

Fonte: Dos autores. (Adaptado de: BOAL, 2015; KOUDELA, 2013; MUNARI et al., 2018; SILVEIRA, 2009; SPOLIN, 2012; VERGÉS et al., 2018).

Revbea, São Paulo, V.16, № 5: 532-546, 2021.

revista brasileira 
Destaca-se que as atividades propostas no Quadro 2 não devem ser cristalizadas e imutáveis, pois isso não condiz com a prática do Teatro do Oprimido e nem com os princípios da Educação Ambiental às quais elas derivam. O educador ambiental, ao praticá-las, deve considerar o ritmo de cada jogador, sua disposição e interesse, podendo oferecer variações e outras possibilidades, desde que se mantenham os seus princípios fundamentais.

Para a abordagem dos temas a serem discutidos e trabalhados durante os jogos, a Figura 2 mostra várias palavras-chave consideradas fundamentais a partir das análises dos trabalhos citados nesta pesquisa para serem desenvolvidas com combinação dos jogos teatrais indicados no Quadro 2.

Figura 2: Palavras-chave relevantes para serem aplicadas nos jogos teatrais.

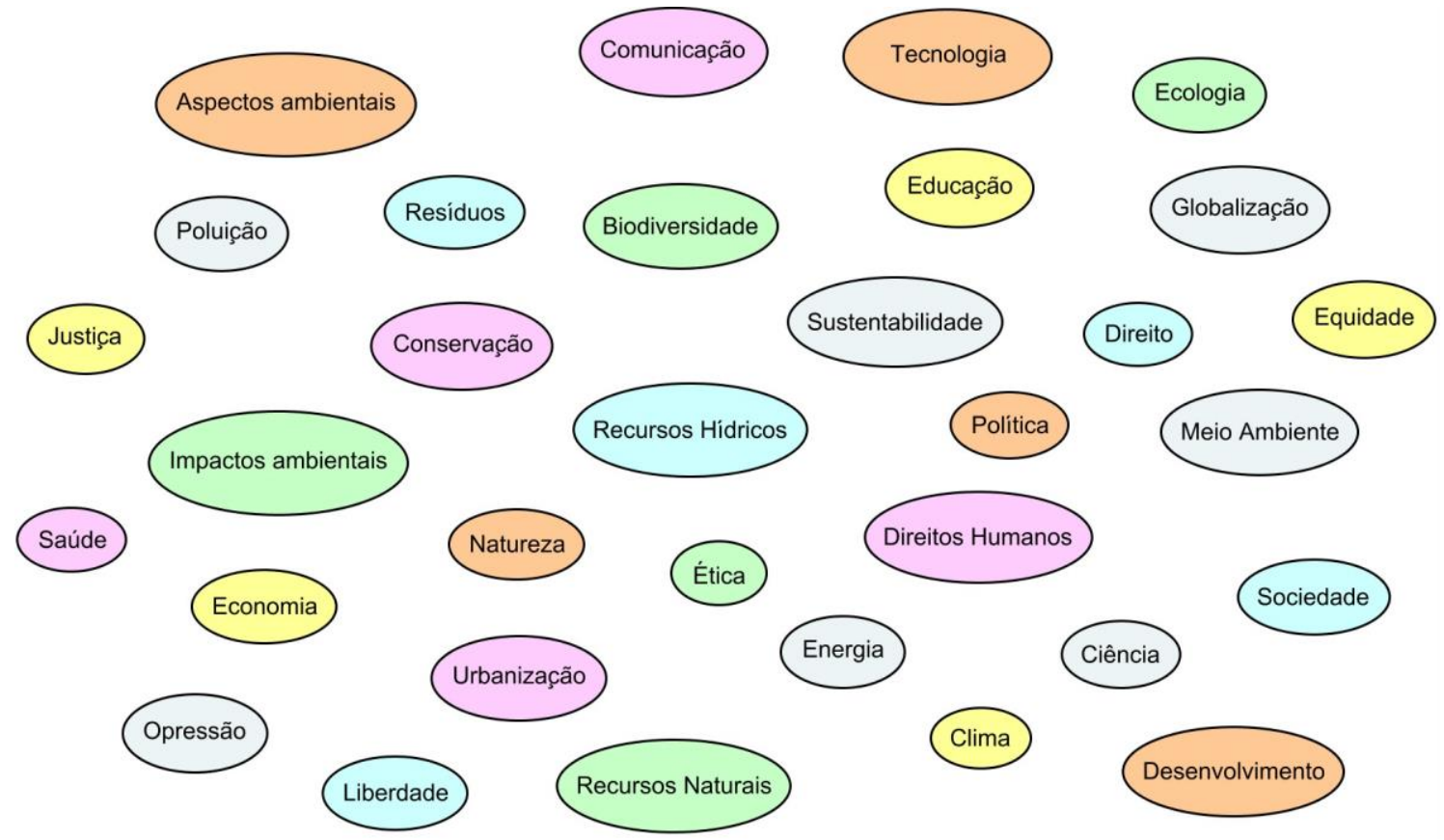

Fonte: Dos autores.

Considerando a nuvem de palavras mostrada na Figura 2, destaca-se que elas se desenvolvam num contexto de reflexão sobre a relação entre os seres humanos e o planeta. Carvalho (2020, p.185) destaca que:

O mundo não existe apenas para nós, humanos. Nós, humanos, estamos aqui graças ao mundo. Somos resultado de um processo evolutivo ocorrido há milhares de anos, que nos permitiu existir. 
decorrentes das atividades antrópicas. Assim, o desenvolvimento cognitivo provocado pelos jogos teatrais torna-se um fator chave, pois é com o auxílio dele que o cidadão buscará melhorar suas relações com o meio ambiente, sua comunidade e o planeta, reconhecendo-se como protagonista responsável pela cocriação de sua própria realidade.

O trabalho realizado por meio da arte é capaz de catalisar a aprendizado e promover ações ambientais em diferentes localidades as quais os sujeitos contatam tais métodos, cultivando a imaginação, ao mesmo tempo em que ajudam os cidadãos a pensar de forma mais crítica e criativa as questões ambientais, contribuindo para a ocorrência de mudanças culturais em direção à sustentabilidade (INWOOD et al., 2017).

Grandes centros urbanos são influenciados por diferentes formas de expressões artísticas, que relacionadas a temática ambiental introduzem meios diferenciados de disseminação de pensamentos, ideias e atitudes capazes de gerar condutas mais éticas e harmônicas, buscando a inovação na solução de problemas ambientais diagnosticados pelo olhar social e encarados pelas comunidades como oportunidades para a construção de soluções sustentáveis (INWOOD et al., 2017).

Alunos que vivenciaram experiências semelhantes, passando por atividades como o "Ecoteatro" relataram gostar dos métodos, pois eles permitem cooperação com amigos, e a oportunidade de fazer algo diferente em sala de aula (ANDRIKOPOULOU; KOUTROUBA, 2017) o que corrobora para a implantação dos jogos teatrais aplicados à Educação Ambiental produzidos neste artigo no ambiente escolar.

\section{Conclusões}

Por meio da aliança entre o Teatro do Oprimido e da Educação Ambiental é possível delinear um conjunto de jogos que atendem aos princípios destas duas linhas do conhecimento, que possuem valores em comum e objetivos semelhantes, e que embasados em processos dialéticos apresentam potencial significativo para a construção de novos valores em busca do desenvolvimento sustentável e justiça social.

Considerando a importância do educador ambiental na transformação coletiva e suas intersecções entre política, meio ambiente, economia e desenvolvimento, os jogos teatrais adaptados para a promoção da Educação Ambiental aqui levantados podem ser ferramentas promissoras para a libertação dos indivíduos perante os sistemas opressores aos quais comummente estão submetidos, o que justifica a sua existência.

A prática dos jogos teatrais, além de desenvolver diferentes tipos de inteligências, diverte, alegra, liberta e envolve os jogadores em aspectos fundamentais do seu dia a dia, trazendo novos olhares sobre as vivências cotidianas, instigando questionamentos e críticas fundamentais ao processo de 
libertação que precede os princípios da Educação Ambiental e do Teatro do Oprimido.

Ademais, por ser uma prática lúdica e inclusiva, ela pode favorecer o protagonismo e expressão de pessoas que muitas vezes não se sentem à vontade em expor a sua opinião e acabam aceitando o que lhes é imposto ou sugestionado.

\section{Agradecimentos}

Ao Conselho Nacional de Desenvolvimento Científico e Tecnológico $(\mathrm{CNPq})$, pelo apoio financeiro à pesquisa - Código de Financiamento 001; ao Programa de Pós-Graduação em Ciências Ambientais (PPGCA) da Universidade Federal de Alfenas.

\section{Referências}

ANDRIKOPOULOU, E.; KOUTROUBA, K. Improvised Eco - Theatre As Educational Tool for the Environmental Awareness of Elementary Students. EDULEARN17 Proceedings, v. 1, n. March, p. 2818-2827, 2017.

BARBOSA, I.; FERREIRA, F. I. Teatro do oprimido e projeto emancipatório: Mutações, fragilidades e combates. Sociedade e Estado, v. 32, n. 2, p. 439463, 2017.

BOAL, A. Jogos teatrais para atores e não atores. 1. ed. [s.I.] Ed. Sesc, 2015. BRASIL. Lei nº 9.795/1999 - Política Nacional de Educação AmbientalDiário da República, $\mathbf{1}^{\text {a }}$ série $\quad \mathrm{n}^{\circ}$ 116, 1999. Disponível em: <https://dre.pt/application/file/67508032>

CARLOS, A. et al. O Teatro do Oprimido aplicado à Educação. Revista Espaço Acadêmico, v. 18, n. 209, p. 119-121, 2018.

CARNEIRO, F.; GONÇALVES, L. A educação libertadora de Paulo Freire e o teatro na educação em saúde : experiências em uma escola pública no Brasil. pro.posições, v. 3, n. 88, p. 401-422, 2015.

CARVALHO, L. C. DE. Pegada Ecológica Adaptada: passos para um futuro melhor. Revista Brasileira de Educação Ambiental, v. 15, n. 5, p. 184-195, 2020.

CHEMI, T. et al. Embodied Performative Approaches: When workplace and theatre innovate together for organizational sustainability. Organizational Aesthetics, v. 9, n. 3, p. 1, 2020.

DANTAS, O. M. DOS S.; DE SANTANA, A. R.; NAKAYAMA, L. Teatro de fantoches na formação continuada docente em Educação Ambiental. Educacao e Pesquisa, v. 38, n. 3, p. 711-726, 2012.

DENIG, S. J. Multiple Intelligences and Learning Styles: Two Complementary Dimensions. Teachers College Record, v. 106, n. 1, p. 96-111, 2004. 
FANTIN, M.; MALCUT, B. Relações entre o Teatro do Oprimido e a mídiaeducação na escola. Contratexto, n. 032, p. 111-132, 2019.

GARCIA, M. A. et al. Duas décadas da PNEA: Avanços e Retrocessos no Brasil. Revista Brasileira de Educação Ambiental, v. 15, n. 5, p. 250-270, 2020.

HERNÁNDEZ GARZÓN, M. Análisis territorial de la problemática ambiental urbana: el caso del municipio de Facatativá, Cundinamarca, Colombia (19802010). Perspectiva Geográfica, v. 24, n. 1, p. 92-115, 2019.

HOELLER, S.; FAGUNDES, M. Educação Ambiental: um caminho possível para a construção de um projeto societário sustentável? Revista Brasileira de Educação Ambiental, v. 15, n. 5, p. 213-229, 2020.

INWOOD, $\mathrm{H}$. et al. ENVIRONMENTAL ARTS. Educational Approaches, p. 223-231, 2017.

IRANMADAR, G.; BOZORGMEHR, S.; SEPAHVAND, M. A Study of the Use of Plays in Improving Multiple Intelligences with A Focus On Verbal and Physical Intelligence. Specialty Journal of Humanities and Cultural Science, v. 2, n. 3, p. 18-30, 2017.

KOUDELA, I. D. Jogos teatrais. 2. ed. [s.I.] Ed. Perspectiva, 2013.

LI, Y.; KRASNY, M. E. Practice change in environmental education: lessons from professional development. Environmental Education Research, v. 25, n. 7, p. 1119-1136, 2019.

LIMA, F. G. DA M.; DOMINGUES, L. H.; VIDOTTI, A. P. Importância Do Conhecimento Sobre Diferentes Tipos De Inteligências No Processo De EnsinoAprendizagem. Revista Cesumar - Ciências Humanas e Sociais Aplicadas, v. 23, n. 1, p. 63, 2018.

LYKESAS, G. et al. THEATRE AND THEATRICAL GAME AS TEACHING METHODS. Sport Science, v. 11, n. 1, p. 23-30, 2018.

MARCONI, M.; LAKATOS, E. Fundamentos de metodologia científica. [s.I: s.n.].

MATIAS, T. P.; MAESTEGHIN, L. T.; IMPERADOR, A. M. A sustentabilidade Ambiental: da utopia à emergência. Revista Brasileira de Educação Ambiental, v. 15, n. 4, p. 160-174, 2020.

MUNARI, A. B. et al. Educação Ambiental e metodologia da problematização aplicadas aos problemas urbanos de Criciúma (SC). Revista Brasileira de Educação Ambiental, v. 13, n. 1, p. 76-86, 2018.

NOGUEIRA CAMPOS, F.; PANÚNCIO-PINTO, M. P.; SAEKI, T. Teatro do oprimido: Um teatro das emergências sociais e do conhecimento coletivo. Psicologia e Sociedade, v. 26, n. 3, p. 552-561, 2014.

OLIVEIRA, T. R. M. DE. Encontros possíveis: experiências com jogos teatrais no ensino de ciências. Ciência \& Educação (Bauru), v. 18, n. 3, p. 559-573, 2012. 
OLIVEIRA, É. C. S.; ARAÚJO, M. DE F. Aproximações do teatro do oprimido com a Psicologia e o Psicodrama. Psicologia: Ciência e Profissão, v. 32, n. 2, p. 340-355, 2012.

PINTO, G. A.; MOREIRA, L. M. O TEATRO NA PESQUISA EM ENSINO DE CIÊNCIAS: DIÁLOGOS COM A PESQUISA EDUCACIONAL BASEADA EM ARTES. Areté, v. 12, n. 6, p. 126-141, 2019.

SÉRGIO GOMES DA, S.; MÁRCIA HELENA VARGAS, M.; TERESA CRISTINA DA SILVEIRA, A. Morcegos: percepção dos alunos do Ensino Fundamental $3^{\circ} \mathrm{e}$ $4^{\circ}$ ciclos e práticas de Educação Ambiental / Bats: perceptions of elementary school students and environmental education practices. Ciência \& Educação (Bauru) Vo - 19, n. 4, p. 859, 2013.

SILVEIRA, E. A arte do encontro: a Educação Estética Ambiental atuando com o Teatro do Oprimido. Educação em Revista, v. 25, n. 3, p. 369-394, 2009.

SPOLIN, V. Jogos Teatrais. 2. ed. [s.I.] Ed. Perspectiva, 2012.

VERGÉS, E. DE A. et al. IMPROVISOS ACONTECEM: EDUCAÇÃO AMBIENTAL ATRAVÉS DE DINÂMICAS TEATRAIS NO AMBIENTE ESCOLAR IMPROVISATIONS HAPPEN: ENVIRONMENTAL EDUCATION THROUGH THEATRICAL DYNAMICS IN THE HIGH SCHOOL. $9^{\circ}$ Forum Internacional de Resíduos Sólidos. Anais...2018

VIEIRA, R. DE C. Jogos teatrais como instrumentos pedagógicos e transformadores de realidades sociais. Paidéia (Ribeirão Preto), v. 20, n. 46, p. 279-280, 2010. 